\title{
The Effects of Job Autonomy, Organizational Learning, and Work Environment on Organizational Commitment of Public Sector Employees in the Ashanti Region of Ghana.
}

\author{
Isaac Ahakwa ${ }^{1}$, Jingzhao Yang ${ }^{1}$, Evelyn Agba Tackie ${ }^{1}$, Leslie Afotey Odai ${ }^{1}$, Samuel Dartey ${ }^{1}$ \\ ${ }^{1}$ School of Management, Jiangsu University, \\ Zhenjiang, Xuefu Road 301, China
}

\begin{abstract}
:
Many employers and researchers across the globe have, over the years, adopted different approaches that can ensure employees' commitment to an organization. This study seeks to find a linkage between Job Autonomy, Organizational Learning, and Work Environment towards Organizational Commitment of public sector employees in Ghana. Data were obtained from three hundred and thirty (330) employees from five (5) Metropolitan, Municipal and Districts Assemblies (MMDAs) in the Ashanti Region of Ghana through the use of simple random probability sampling. However, three hundred and fifteen (315) accurate responses were used in the analysis due to incomplete and missing figures. Data were analyzed using partial least squared based on Structural Equation Modeling (SEM). The findings revealed that organizational learning has the most incredible impact on organizational commitment and was statistically significant at $p<$ 0.05. This finding provides useful suggestions for institutions, employers, and policymakers to promote organizational learning among employees through in-service training, knowledge distribution, and group behavior. The result can serve as a practical tool to boost organizational commitment towards achieving organizational goals.
\end{abstract}

Keywords: Organizational Commitment, Job Autonomy, Organizational Learning, Work Environment, Ghana.

\section{Introduction}

Historical research indicates that many scholars have researched into understanding the existence, predictors, and implications of an organization's employees' commitment. Organizational commitment is essential because it can contribute to different beneficial corporate results when established. Fostering organizational commitment among employees is very significant, according to Yahaya and Ebrahim (2016), because employees who are intensely committed to their organizations are likely to stay longer, have better results, and appear to be highly active in the workplace. Also, dedicated workers in their companies demonstrate loyalty and become active individuals (Dey, Kumar, \& Kumar, 2014). Consequently, committed workers display a constructive approach to organizational priorities and values that are likely to cultivate positive behavior. Employee commitment is connected with many positive behavioral results, such as employee retention, participation, efficiency, job excellency, and personal dedication in achieving organizational goals (Hanaysha, 2016).
Organizational commitment, primarily to business organizations' management, is considered an essential issue because work satisfaction is related to organizational commitment, and both are directly related to corporate sustainability and higher productivity (Abdullah \& Ramay, 2012). Some scholars have also stated that organizational commitment directly impacts employees' performance and is therefore seen as an essential issue (NGUYEN \& TU, 2020; Siders, George, \& Dharwadkar, 2001; Sungu, Weng, Hu, Kitule, \& Fang, 2020). It is evident in previous studies that many variables are affecting organizational commitment.

Ghana's public sector employees' commitment problems have varied over the years and reformed efforts to address them (Ayee, 2008). Over the years, Ghana's governments have pursued various reform styles to tackle those issues-from early post-independence human resources growth through first-generation and second-generation quantitative reforms in the $80 \mathrm{~s}$ and 90 s to current third-generation 
is service delivery reforms. (Owusu, 2012). However, lack of organizational support due to a high level of political interference continues to be a major problem faced by the public sector of Ghana. This problem affects the organizational commitment of employees, which in turn reduces productivity. Myjoyonline (2019) report revealed that Ghana's poor public sector system is reflected in its falling rankings on the Ease of Doing Business index compiled by the World Bank. The latest report for 2019 ranked Ghana114 ${ }^{\text {th }}$ with a score of 60.4 , and in 2020 , the country is ranked $118^{\text {th }}$ with a score of 60 . A recent study by Kumasey, Bawole, and Hossain (2017) used a code of ethics to predict public service employees' organizational commitment and found a significant positive effect between them. Uncommitted employees have several consequences to the organization and the public, including underperformance of public sector organizations, lack of job security, and low trust etc. Therefore one's relationship of commitment with an entity must be examined. Unfortunately, the literature concerning the relationship, particularly in the Ghanaian context, is of minimal quality, considering the significance and complexity of these problems. This study will give organizations in Ghana indigenous empirical evidence to create and implement policies and practices that encourage employee organizational commitment. In this regard, this study is aimed at examining how Job Autonomy, Organizational Learning and Work Environment create an environment for enhanced organizational commitments.

\section{Literature Review and Hypothesis Development}

\subsection{Organizational Commitment}

It is undeniably essential for organizations to develop organizational commitment since employees are the vital bases of sustainable success and efficiency. Organizational commitment has previously been described as a psychological approach that binds workers to an organization to decrease turnover intent (Farrukh, Wei Ying, \& Abdallah Ahmed, 2016). Zaraket (2017) proposed the most generally accepted definition of organizational commitment as "the degree to which an individual participates in his institute." Additionally, loyalty is demonstrated by a worker's ability to successfully work in an institution and his desire to sustain the relationship without attempting to leave for another institution (Zaraket, 2017). The significance of organizational commitment has been recorded in the literature. Organizations appear to be concerned with having very committed personnel. It is widely agreed that organizational commitment could lead to different results, such as lower turnover levels, increased enthusiasm, improved institution's conduct, and constant corporate support (Kwon \& Banks, 2004). Committed personnel often work harder to fulfill institutional objectives and appear to positively receive their values (Cheah, Chong, Yeo, \& Pee, 2016). In this framework, it can be understood that many positive behavioral results can be correlated with personnel commitment, such as more excellent retention of workers, motivation, efficiency, quality of work, and willingness to make sacrifices to enhance the reputation and performance of organizations (Farrukh, Ying, \& Mansori, 2017).

Based on the discussion above, it can be understood that organizational commitment is a vital literature subject and is respected by my scholars and experts as it has positive consequences for the organization's performance. Organizational commitment is the main element in assessing organizations' competitiveness, which increases employee morale and loyalty (Hayat, Azeem, Nawaz, Humayon, \& Ahmed, 2019; N. Hendri, 2019; Yousef, 2017). Organizational commitment often has a clear correlation with the actions and performance of employees. If an employee has an organizational commitment, there will be fewer chances for absence and turnover (R. Ahmad, Islam, \& Saleem, 2019; Igbaria \& Greenhaus, 1992; Joe-Akunne \& Ezeh, 2019; Karunarathne \& Wickramasekara, 2020). Therefore, it is crucial to regularly review employees' commitment to resolving any problems which may arise and ensure that employees maintain a positive attitude to work, which is necessary for overall organizational success.

\subsection{Job Autonomy}

A study by Lu, Brockner, Vardi, and Weitz (2017) suggests autonomy as a critical focus of work design (Smith, 2003), a kind of independence or state of being independent, free and self-directed. Self-Determination Theory is based on the concept of autonomy that was implemented in the 1970s when the emphasis was on intrinsic and extrinsic rewards (Pfister \& Lukka, 2019) and by applying these rewards to the three essential needs of that theory, thus, autonomy, competence, and interdependence (Deci \& Ryan, 2010). A study on self-determination theory indicates that the more autonomous the individual's excitement is, the greater their determination and performance for the company, resulting in a more self-motivation and self-determination towards work (Niemiec \& Ryan, 2009). 
Job autonomy, therefore, shows the level at which a job allows routine work to be free, self-determined, and careful, to make decisions and select methods used to perform everyday tasks (Morgeson, Delaney-Klinger, \& Hemingway, 2005). A similar perception of autonomy was recognized as the notch to which an organization enabled independence and cautiousness in work activities (Dee, Henkin, \& Chen, 2000). Job autonomy is also recognized as an individual's preference, posing additional questions regarding whether workers view themselves as autonomous in moral decision-making (Abdolmaleki, Lakdizaji, Ghahramanian, Allahbakhshian, \& Behshid, 2018). Still, when it comes to an organization's culture, autonomy is a role brooch, a pointer to the skill and accountability criteria of a job, and, perhaps, an opportunity for consistent and competent results (Ilyash, Yildirim, Capuk, \& Bozgul, 2019).

Most theorists have investigated that workers should be encouraged to act in an obligatory manner (Coeckelbergh, 2006). As a result, it leads to organizational success by understanding their duties (Driedonks, Gevers, \& van Weele, 2010), but this often leads to a moderate exaggeration of the importance of autonomy (S. Naqvi, Kanwal, Ishtiaq, \& Ali, 2013). If everyone begins to enjoy a high amount of independence, limitations must be imposed (Nnamaganda, 2019). The objections to liberally high freedom exist in the literature, which comprises a misconception of a person's identity, the disproof of fairness principles, unaccountability for rational actions of control, and no sensitivity to the importance of personal associations (Đerić, 2020). That would be a vital sign of a lack of job satisfaction of an employee within the organization. However, the relationship between autonomy and organizational performance was positively correlated in a meta-analysis (Marchese \& Ryan, 2001).

\subsubsection{The link between Job Autonomy and Organizational Commitment}

More studies have shown a significant and positive relationship between job autonomy and organizational commitment (Dude, 2012; Karim, 2017; Khan, Kumar, \& Vytialingam, 2016; S. R. Naqvi, Ishtiaq, Kanwal, \& Ali, 2013; Park \& Searcy, 2012). Lin and Ping (2016) discovered a weak relationship between the two variables. The survey conducted by Jain and Duggal (2018) revealed that transformational leadership positively influences employees' organizational commitment via job autonomy. Therefore, the concept is straightforward; when employees see themselves as having discretionary power in the performance of their corporate roles, they have a better chance to remain in their current organizations due to increased ownership of work (Moe, Dahl, Stray, Karlsen, \& Schjødt-Osmo, 2019). Given the above writings, the following hypothesis is proposed:

H1: Job autonomy has a significant positive impact on organizational commitment.

\subsection{Organizational Learning}

Organizational learning is considered the best recommendation in today's unpredictable environment to improve institutional performance. Bates and Khasawneh (2005), organizational learning is the attainment, distribution, and sharing of information, reinforcing and promoting continuous learning and its application to organizational enhancement. Also, organizational learning is collecting administrative activities that include acquiring information, information distribution, and information interpretation, which have mindful or insentient effects on positive corporate philosophy (Bates \& Khasawneh, 2005).

Mehrabi, Jadidi, Haery, and Alemzadeh (2013) have shown that learning gives a company the utmost economical advantage. According to Loon Hoe and McShane (2010), organizational learning enhances an institution's capability to facilitate and use the skills required to respond to external environmental factors. Usefi, Nazari, and Zargar (2013) revealed that a lack of focus on organizational learning reduces organizations' success and may result in low productivity and efficiency, making it impossible for organizations to progress. The main feature of a learning organization's ability to pursue opportunities to study from useful sources and then utilize this information to give the institution added value through an exchange of knowledge in organizations (Ramírez, Morales, \& Rojas, 2011). A. Ahmad and Marinah (2013), being a learning organization and improving training courses are critical factors required to enhance learning, strengthen knowledge management, develop individual and institutional performance, and retain an economic advantage.

\subsubsection{The link between Organizational Learning}

\section{and Organizational Commitment}

Past research works have revealed that organizational learning has a substantial effect on organizational commitment (Addai, Ofori, Avor, \& Tweneboah, 
2017; Hanaysha, 2016; M. I. Hendri, 2019; Hsu, 2009; Salarian, Baharmpour, \& Habibi, 2015; Usefi et al., 2013). The research work by A. Ahmad and Marinah (2013) established a strong correlation between organizational learning and organizational commitment. The researcher suggested that to keep up with the rapidly changing world, organizations need to remain agile and strengthen their commitment to employees through organizational learning. Similarly, Ong, Kasim, and Uli (2008) have shown a significant positive relationship between organizational learning and organizational commitment. Also, (Naim \& Lenka, 2018) revealed that organizational learning directly affects affective commitment. Furthermore, Wang (2007) confirmed that the broadening and promotion of an organizational learning culture is a crucial mechanism for promoting employee satisfaction, organizational commitment, and maintaining a safe and stable workforce in the long term. That means that organizational learning can increase organizational commitment among personnel and contribute to positive work effects. Given the above writings, the following hypothesis is proposed:

$\mathrm{H} 2$ : Organizational learning has a significant positive association with organizational commitment.

\subsection{Work Environment}

The working environment is a critical factor that influences employee fulfillment and dedication to the organization. The working environment refers to the area of an institution in which its workers do their job. Danish, Ramzan, and Ahmad (2013) stated that the working environment is linked to a specific company's atmosphere in which its workers conduct their duties. Undoubtedly, since their desires are possible to be fulfilled, a facilitative and healthy work atmosphere will attract employees. To succeed, companies should design their working environments to increase the degree of commitment and motivation of employees that would eventually contribute to favorable results. A right working environment includes all the elements of a job, such as the amenities to perform responsibilities, a contented workspace, protection, and no noise. Hanaysha (2016) found that, relative to those who feel insecure, workers who feel relaxed with their working environment are likely to work more efficiently and enjoy the working process. Managers should also strengthen the elements of the work environment to warrant the well-being of their personnel.
Prior research demonstrates that the work environment can be measured in many respects. Jernigan, Beggs, and Kohut (2016) indicated that the work environment involves involvement, team cohesion, supervisors; role coordination; work stress; autonomy; precision, creativity, physical well-being, and management power. Likewise, Aneela (2012) carried out meta-analysis scrutiny and established numerous work environment features in the literature. These included the psychological setting, work settings, corporate philosophy, and institutional climate. Hanaysha (2016) also identified a range of dimensions for the work environment evaluation, including: "job difficulty, job autonomy, concern of leadership, facilitation of leadership, working group cooperation, workgroup spirit, position uncertainty, fairness and reward system equity. Therefore, the work environment may be evaluated as any factor influencing personnel's actions in an institution.

\subsubsection{The link between Work Environment and Organizational Commitment}

A range of studies has established a significant and positive connection between work environment and organizational commitment (Abdullah \& Ramay, 2012; Hanaysha, 2016; Khuong \& Le Vu, 2014; Vanaki \& Vagharseyyedin, 2009). Pitaloka and Sofia (2014) found that job satisfaction positively impacts organizational commitment in a conducive work environment. Therefore, job satisfaction and organizational commitment are the foundations of positive behavior for corporate citizenship and encourage employees to work firmer to achieve organizational objectives. Haggins (2011) also established that the work environment is essential to attain employees' organizational commitment. By Giffords (2009), the significant impact on organizational commitment is the working environment. Given the above writings, the following hypothesis is proposed:

H3: Work environment has a significant positive influence on organizational commitment.

\subsection{The Conceptual Framework}

Based on the literature reviewed, the conceptual framework for this study is presented below. 


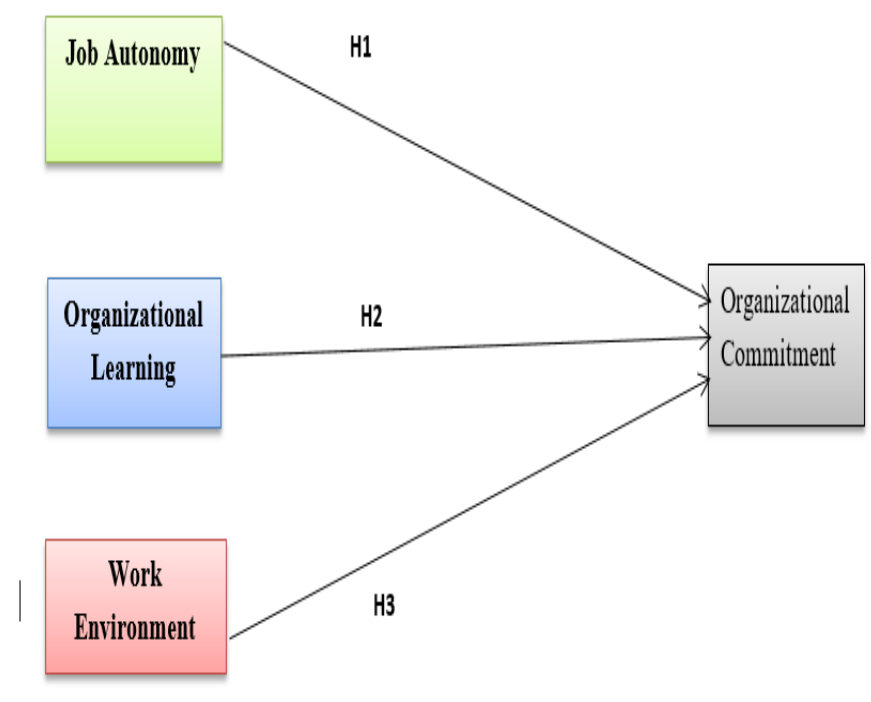

Figure 1: Conceptual Framework

\section{Methodology}

\subsection{Research Design}

A research design is a collection of procedures and methods for collecting and analyzing measurements of factors recognized in a research problem (Halldorsson, Castelijn, \& Creswell, 2019). The study used quantitative methods to analyze classification features, measure figures, and create a statistical pattern to test hypotheses and clarify findings.

\subsection{Measurement of Variables}

In construct measurement, the questionnaire was structured to evaluate the relationship between four (4) primary constructs: organizational commitment as the dependent variable, job autonomy, organizational learning, and work environment as independent variables. The organizational commitment was measured using four (4) items formulated by Mowday, Steers, and Porter (1979). Also, job autonomy was measured with four (4) items adopted from Breaugh (1985). Organizational learning was also measured with an overall number of five (5) items developed by Joo and Park (2010), and also work environment was measured with a total number of four (4) items, which was adopted from McGuire and McLaren (2009). The items selected were measured on a five-point Likert scale with the scale limits stretching from strongly disagree (1) to strongly agree (5).

\subsection{Study Area}

The study was conducted in the Ashanti Region of Ghana. The study population consisted of employees of MMDAs in the Ashanti Region of Ghana. The study selected five (5) well-known MMDAs in the Ashanti Region of Ghana. These include Kumasi Metropolitan Assembly, Ejisu Municipal Assembly, Oforikrom Municipal Assembly, Juaben Municipal Assembly, and Asante Akim Central Municipal Assembly.

\subsection{Data Collection instrument and procedure}

Data was collected through a structured questionnaire. An online-accessible survey was rendered to three hundred and thirty (330) employees at the five MMDAs in the Ashanti Region of Ghana. That was done through the use of simple random probability sampling.

Three hundred and fifteen (315) accurate responses were retrieved out of the 330 overall survey responses. The remaining fifteen (15) were considered invalid and therefore omitted as they were either substantially incomplete responses or had missing values. In analyzing data with structural equation modeling (SEM), a sample size of 100 and above is deemed good statistically (Hair $\mathrm{Jr}$ et al., 2016). Therefore, the sample size of 315 satisfies these criteria, and it is, consequently, sufficiently relevant to obtain robust test results.

\subsection{Data Analysis}

For easy accessibility and transition to the various research tools, data was transferred from the online survey questionnaire portal into Microsoft Excel format. The study included both exploratory and confirmatory studies to verify the validity of the model. To determine the samples' demographic profile, SPSS version 23.0 was used to process the descriptive statistics. Partial Least Squares (PLS) analysis with SmartPLS 3.0 software was used to analyze the study model. We checked the measurement model for the validity and reliability of the measures. We then examined the structural model according to the recommended two-stage analytical procedures for SEM (Hair Jr, Hult, Ringle, \& Sarstedt, 2016). A bootstrapping method (5000 resamples) was used to test the path coefficients' significance and loadings (Hair Jr et al., 2016). Because Structural Equation Modeling (SEM) allows data not to break the normality assumption, data normality has been checked. 


\section{Research Results}

\subsection{Demographic Profile}

Table 1: Respondent's Profile

\begin{tabular}{llr}
\hline $\begin{array}{l}\text { Demographic } \\
\text { Characteristics }\end{array}$ & & $\%$ \\
\hline Gender & Male & 51.7 \\
& Female & 48.3 \\
& $18-25$ years & 14.3 \\
Age & $26-35$ years & 49.2 \\
& $36-45$ years & 30.2 \\
& 46 years and above & 6.3 \\
Qualification & Diploma certificate & 20.3 \\
& Bachelor degree & 54.6 \\
& Post-graduate degree & 15.2 \\
& Other certificates & 9.8 \\
Work Experience & Less than one year & 2.3 \\
& Between 1 to 2 years & 17.7 \\
& Between 2 to 5 years & 50.2 \\
& Above five years & 29.8 \\
\hline
\end{tabular}

Respondents' descriptive statistics showed that $51.7 \%$ of the overall response are males, while females accounted for $48.3 \%$. The findings also revealed that $14.3 \%$ of those respondents were 18 to 25 years of age, $49.2 \%$ were 26 to 35 years of age, $30.2 \%$ were 36 to 45 years of age, while $6.3 \%$ were 46 years of age or older. Also, the demographic findings showed that $2.3 \%$ had below one year of work experience at their present organizations, $17.7 \%$ had 1-2 years of experience, $50.2 \%$ had 2-5 years of work experience, and $29.8 \%$ had more than five years of work experience. Finally, Table 1 indicates that $20.3 \%$ of respondents had a diploma certificate, $54.6 \%$ had a bachelor's degree, $15.2 \%$ had a post-graduate degree (either a master's degree or a doctoral degree), $9.8 \%$ had other certificates.

\subsection{Evaluation of the Measurement Model}

Data obtained were analyzed for internal consistency reliability, convergent, and discriminant validity. The outer loadings, average variance extracted (AVE), composite reliability, and Cronbach $\alpha$ were based on Hair Jr et al.'s (2016) criterion shown in table 2.
Table2: Validity and reliability for constructs.

\begin{tabular}{|c|c|c|c|c|c|}
\hline Constructs & $\begin{array}{l}\text { Notat } \\
\text { ions }\end{array}$ & $\begin{array}{l}\text { Loadi } \\
\text { ngs }\end{array}$ & AVE & $\begin{array}{l}\text { Cron } \\
\text { bach } \\
\alpha\end{array}$ & $\begin{array}{l}\text { Compo } \\
\text { site } \\
\text { Reliabi } \\
\text { lity }\end{array}$ \\
\hline \multirow{4}{*}{$\begin{array}{l}\text { Organizational } \\
\text { Commitment }\end{array}$} & OC1 & 0.750 & \multirow{4}{*}{0.618} & \multirow{4}{*}{0.794} & \multirow{4}{*}{0.866} \\
\hline & OC2 & 0.798 & & & \\
\hline & OC3 & 0.796 & & & \\
\hline & OC4 & 0.801 & & & \\
\hline \multirow{4}{*}{ Job Autonomy } & JA1 & 0.842 & \multirow{4}{*}{0.673} & \multirow{4}{*}{0.839} & \multirow{4}{*}{0.892} \\
\hline & JA2 & 0.785 & & & \\
\hline & JA3 & 0.839 & & & \\
\hline & JA4 & 0.815 & & & \\
\hline \multirow{5}{*}{$\begin{array}{l}\text { Organizational } \\
\text { Learning }\end{array}$} & OL1 & 0.722 & \multirow{5}{*}{0.587} & \multirow{5}{*}{0.824} & \multirow{5}{*}{0.876} \\
\hline & OL2 & 0.748 & & & \\
\hline & OL3 & 0.755 & & & \\
\hline & OL4 & 0.795 & & & \\
\hline & OL5 & 0.806 & & & \\
\hline \multirow{4}{*}{$\begin{array}{l}\text { Work } \\
\text { Environment }\end{array}$} & WE1 & 0.846 & \multirow{4}{*}{0.742} & \multirow{4}{*}{0.884} & \multirow{4}{*}{0.920} \\
\hline & WE2 & 0.860 & & & \\
\hline & WE3 & 0.908 & & & \\
\hline & WE4 & 0.829 & & & \\
\hline
\end{tabular}

Note: OC, (Organizational Commitment); JA, (Job Autonomy); OL, (Organizational Learning); WE, (Work Environment)

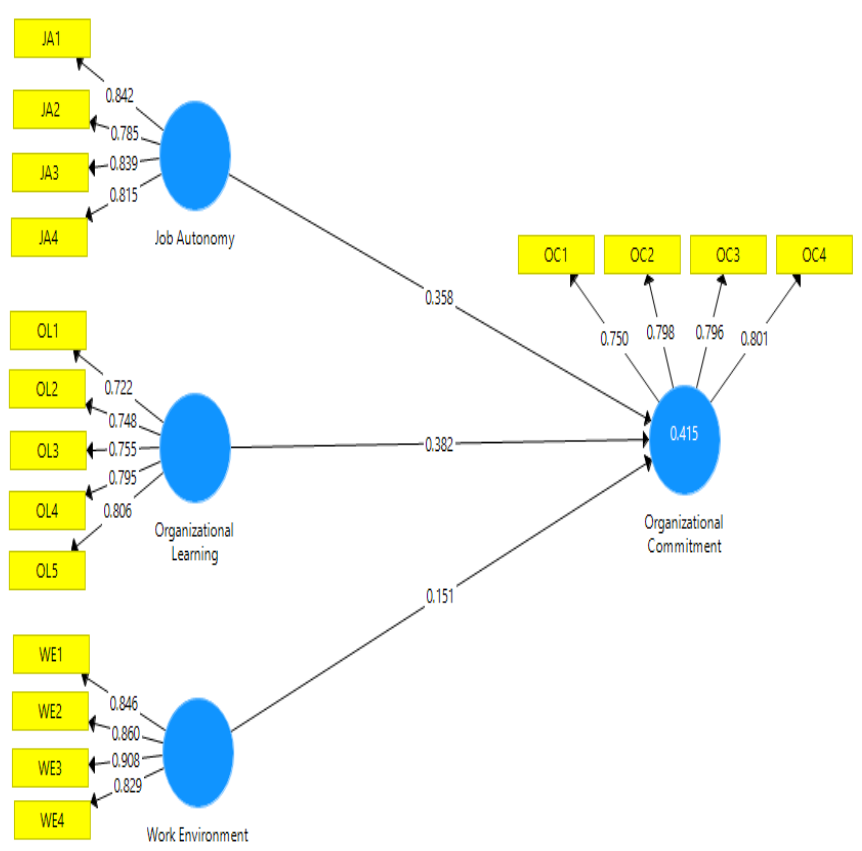

Figure 2: Structural Model

Convergent validity of the model was tested through factor loadings, Cronbach Alpha, Composite Reliability (CR), and Average Variance Extracted (AVE). All the item loadings in table 2 were above the threshold of 0.6 (Chin, Peterson, \& Brown, 2008). The Cronbach alpha, which is the measure of internal consistency of the set of items, exceeded the recommended value of 0.70 (Hair $\mathrm{Jr}$ et al., 2016). Composite reliability values, which present the degree to which the construct indicators indicate the latent construct, exceeded the threshold value of 0.7 while average variance extracted, which reflect the 
total measure of variance in the latent structure indicators, surpassed the suggested value of 0.5 (Hair Jr et al., 2016).

Table 3: Collinearity Value Assessed by VIF

\begin{tabular}{|l|c|}
\hline Items & Collinearity Values \\
\hline JA1 & 1.890 \\
\hline JA2 & 1.667 \\
\hline JA3 & 2.172 \\
\hline JA4 & 1.763 \\
\hline OC1 & 1.437 \\
\hline OC2 & 1.708 \\
\hline OC3 & 1.614 \\
\hline OC4 & 1.632 \\
\hline OL1 & 1.546 \\
\hline OL2 & 1.672 \\
\hline OL3 & 1.806 \\
\hline OL4 & 1.690 \\
\hline OL5 & 1.843 \\
\hline WE1 & 2.412 \\
\hline WE2 & 2.109 \\
\hline WE3 & 1.785 \\
\hline WE4 & 2.032 \\
\hline
\end{tabular}

Table 3 shows the collinearity values of the various constructs assessed using VIF. The VIF values for all the constructs are lower than the threshold of 5, suggesting no collinearity problems in the model (Kim, 2019).

Table 4: Discriminant Validity

\begin{tabular}{|l|c|c|c|c|}
\hline Constructs & 1 & 2 & 3 & 4 \\
\hline Job Autonomy & $\mathbf{0 . 8 2 1}$ & & & \\
\hline Organizational & 0.489 & $\mathbf{0 . 7 8}$ & & \\
Commitment & & $\mathbf{6}$ & & \\
\hline Organizational & 0.338 & $\begin{array}{l}0.53 \\
\text { Learning }\end{array}$ & $\begin{array}{l}\mathbf{0 . 7 6} \\
\mathbf{6}\end{array}$ & \\
\hline Work Environment & 0.014 & $\begin{array}{l}0.23 \\
8\end{array}$ & $\begin{array}{l}0.21 \\
4\end{array}$ & $\begin{array}{l}\mathbf{0 . 8 6} \\
\mathbf{1}\end{array}$ \\
\hline
\end{tabular}

Values on the diagonal (bolded) are the AVE's square root, while the off-diagonals are correlations.

Table 5: Heterotrait-monotrait (HTMT)

\begin{tabular}{|l|r|r|r|r|}
\hline Constructs & 1 & 2 & 3 & 4 \\
\hline Job Autonomy & & & & \\
\hline $\begin{array}{l}\text { Organizational } \\
\text { Commitment }\end{array}$ & 0.587 & & & \\
\hline $\begin{array}{l}\text { Organizational } \\
\text { Learning }\end{array}$ & 0.398 & 0.648 & & \\
\hline $\begin{array}{l}\text { Work } \\
\text { Environment }\end{array}$ & 0.049 & 0.276 & 0.241 & \\
\hline
\end{tabular}

Shaded boxes are the standard reporting format for the HTMT procedure.
To assess the discriminant validity, which represents the degree to which the measures are not replicating some other variables; this is indicated by low correlations between the measure of interest and the measures of other constructs. Table 4 shows that each construct's AVE square root (diagonal values) is greater than its corresponding correlation coefficients, suggesting sufficient discriminant validity (Fornell \& Larcker, 1981).

Some current disapprovals of the Fornell and Larcker (1981) criteria indicate that they do not effectively identify an absence of discriminant validity (Henseler, Ringle, \& Sarstedt, 2015). Henseler et al. (2015) advocated an alternative approach to measure the discrimination validity of the heterotrait-monotrait (HTMT) ratio of correlation based on the multi-trait-multimethod matrix. This new method was used to test the discriminant validity, and the findings are presented in Table 5 . When the HTMT value is larger than the threshold value of 0.85 (Kline, 2011) for the first criterion, there is a problem with discriminant validity. However, as presented in Table 5, all the values were below the HTMT value of 0.85 .

\subsection{Evaluation of the Structural Model and Hypotheses Testing}

Table 6: Structural estimates (Hypotheses testing)

\begin{tabular}{|l|c|c|c|c|c|}
\hline $\begin{array}{l}\text { Hyp } \\
\text { othe } \\
\text { ses }\end{array}$ & $\begin{array}{c}\text { Path } \\
\text { Coefficie } \\
n t(\beta)\end{array}$ & $\begin{array}{c}\text { t-statis } \\
\text { tics }\end{array}$ & $e^{p \text {-valu }}$ & $\begin{array}{c}f \\
\text { square } \\
\left(f^{2}\right)\end{array}$ & Decision \\
\hline $\begin{array}{l}\text { JA } \\
\text { OC }\end{array}$ & 0.358 & $7.349^{*}$ & 0.000 & 0.192 & Supported \\
\hline $\begin{array}{l}\text { OL } \\
\text { OC }\end{array}$ & 0.382 & $7.643^{*}$ & 0.000 & 0.210 & Supported \\
\hline $\begin{array}{l}\text { WE } \\
\text { OC }\end{array}$ & 0.151 & $3.489^{*}$ & 0.000 & 0.037 & Supported \\
\hline
\end{tabular}

Note: Critical t-statistics, $* 1.96(\mathrm{P}<0.05)$

Table 7: Predictive Relevance

\begin{tabular}{|l|c|c|c|}
\hline Construct & $R^{2}$ & Adjusted $R^{2}$ & $Q^{2}$ \\
\hline OC & 0.415 & 0.409 & 0.245 \\
\hline
\end{tabular}

To measure the structural model, we looked at the $R^{2}$, $\beta$, and corresponding t-statistics through the 5000 resample bootstrapping process suggested by Hair Jr et al. (2016). They also recommended that researchers report on predictive significance $\left(Q^{2}\right)$ and effect sizes $\left(f^{2}\right)$ together with the basic measures. First 
and foremost, we assessed the relationships between the variables. Job autonomy positively and significantly affected organizational commitment $(\beta$ $=0.358$, t-statistics $=7.349, \mathrm{p}<0.05)$, and organizational learning positively and significantly affected organizational commitment $(\beta=0.382$, $t$-statistics $=7.643 \mathrm{p}<0.05)$. Work environment also positively and significantly affected organizational commitment $(\beta=0.151$, t-statistics $=3.489$. $\mathrm{p}<$ $0.05)$. Therefore, $\mathrm{H} 1, \mathrm{H} 2$, and $\mathrm{H} 3$ were all supported (See Table 6). Furthermore, job autonomy, organizational learning, and work environment explain $41.5 \%$ of the total amount of variance in organizational commitment; thus, $R^{2}=0.415$, which is higher than the threshold value of 0.26 proposed by Cohen (1988), and this indicates that the model is substantial.

Next, we assessed the effect sizes $\left(f^{2}\right)$. As a result, the p-value shows the relationship's significance; however, its impact does not show. Hence, data and findings are challenging to be understood by readers. Therefore, substantial significance $\left(f^{2}\right)$, as well as statistical significance (p), must be reported. Hair Jr et al. (2016) proposed that variations in the $R^{2}$ value must be tested. Cohen's (1988) guidelines were used to measure the effect size, which are 0.02 for small effects, 0.15 for medium effects, and 0.35 for large effects. Table 6 shows that organizational learning had the most significant positive, strong effects on organizational commitment with an $f^{2}$ value of 0.210 , followed by job autonomy with significant positive, strong effects on organization commitment with an $f^{2}$ value of 0.192 . Last, the work environment had a substantially positive medium effect on organizational commitment with an $f^{2}$ value of 0.037 .

The predictive sample reuse technique $\left(Q^{2}\right)$, in addition to the size effect of the $R^{2}$ and $f^{2}$, can effectively demonstrate predictive relevance (Chin et al., 2008). Based on the blindfolding technique, $Q^{2}$ displays how well data can be reassembled empirically through the model and the PLS parameters. For this study, we acquired our $Q^{2}$ through cross-validated redundancy procedures. A $Q^{2}$ value bigger than zero (0) means that the model has predictive relevance; however, a $Q^{2}$ value below 0 means the model's predictive relevance lacks. Therefore, our $Q^{2}$ value of 0.245 in table 7 suggested that the model had acceptable predictive relevance.

\section{Discussion, Conclusion, and Recommendation}

\subsection{Discussion and Conclusion}

The study aimed to analyze the effects of job autonomy, organizational learning, and work environment on organizational commitment among public sector employees in the Ashanti region of Ghana. The findings disclosed that job autonomy has a significant positive influence on organizational commitment and is comparable to some past studies that found job autonomy to be an essential determinant of organizational commitment (Dude, 2012; Karim, 2017; Khan et al., 2016; S. R. Naqvi et al., 2013; Park \& Searcy, 2012). This outcome recommends that if employees are given autonomy at the workplace, their commitment toward the organization or institution will be high.

Also, the findings disclosed that organizational learning has a significant positive influence on organizational commitment. More fantastic support was reported in several prior studies, which found organizational learning as a critical element in influencing organizational commitment (Addai et al., 2017; Hanaysha, 2016; M. I. Hendri, 2019; Hsu, 2009; Salarian et al., 2015; Usefi et al., 2013). The findings indicate that organizational learning philosophy can be seen as a fundamental indicator of an employee's loyalty to an organization. Therefore, it is essential to concentrate on organizational learning and guarantee a continuous learning philosophy among employees through training courses, distribution of knowledge, and group behavior. That will help organizations tackle issues concerning organizational commitment and increase their effectiveness in doing business. The results of organizational learning are fundamental to corporate efficiency and increased success.

Moreover, this paper's results show that the working environment has a substantial positive impact on organizational commitment and is consistent with previous studies. (Abdullah \& Ramay, 2012; Hanaysha, 2016; Khuong \& Le Vu, 2014; Vanaki \& Vagharseyyedin, 2009). That means that the work environment is a critical factor affecting employees' commitment level in public sectors. Therefore, this result's practical implication suggests that authorities in charge of public sector institutions should be aware of the importance of designing a conducive environment in creating organizational commitment among their workforces. For example, the provision of leisure facilities and preserving a green and sanitary environment can play a central role in coaxing employees' actions. Moreover, the layout of 
the workplace and organizational culture are also fundamental to enhance organizational commitment.

\subsection{Limitations and Recommendations}

This study has some drawbacks that will provide opportunities for future studies. For example, the sample was chosen using a simple random sampling method that cannot represent the whole population. The variables used in this research work with a greater sample size may also be retested for further research so that the results are generalized to more populations. Also, the study did not involve people outside the public sector as well as outside Ghana. Future research may also be performed to address the limitations described by expanding the research to other settings and countries to achieve an extensive generalization of the analysis. Finally, this analysis used the form of data collection surveys. It would also be necessary to replicate this research using in-depth interviews.

\section{References}

[1] Abdolmaleki, M., Lakdizaji, S., Ghahramanian, A., Allahbakhshian, A., \& Behshid, M. (2018). Relationship between autonomy and moral distress in emergency nurses. Indian J Med Ethics, 6, 1-5.

[2] Abdullah, A., \& Ramay, M. (2012). Antecedents of organizational commitment of banking sector employees in Pakistan. Serbian Journal of Management, 7(1), 89-102.

[3] Addai, P., Ofori, I. N., Avor, J., \& Tweneboah, D. N. (2017). Organizational learning and job complexity as predictors of commitment among employees at nestle Ghana limited. International Journal of English Literature and Social Sciences, 2(6), 239247.

[4] Ahmad, A., \& Marinah, A. (2013). Learning organization and organizational commitment in schools. Journal of Research, Policy \& Practice of Teachers and Teacher Education, 3(1), 18-25.

[5] Ahmad, R., Islam, T., \& Saleem, S. (2019). How commitment and satisfaction explain leave intention in the police force? Policing: an international journal.

[6] Aneela, M. (2012). Work environment, burnout, organizational commitment, and role of personal variables as moderators. Quaid-i-Azam University, Islamabad.

[7] Ayee, J. R. (2008). Reforming the African Public Sector. Retrospect and Prospects:
Retrospect and Prospects: African Books Collective.

[8] Bates, R., \& Khasawneh, S. (2005). Organizational learning culture, learning transfer climate, and perceived innovation in Jordanian organizations. International journal of training and development, 9(2), 96-109.

[9] Breaugh, J. A. (1985). The measurement of work autonomy. Human Relations, 38(6), 551-570.

[10] Cheah, C. S., Chong, V. S. W., Yeo, S. F., \& Pee, K. W. (2016). An empirical study on factors affecting organizational commitment among generation X. Procedia-Social and Behavioral Sciences, 219, 167-174.

[11] Chin, W. W., Peterson, R. A., \& Brown, S. P. (2008). Structural equation modeling in marketing: Some practical reminders. Journal of Marketing Theory and Practice, 16(4), 287-298.

[12] Coeckelbergh, M. (2006). Regulation or responsibility? Autonomy, moral imagination, and engineering. Science, Technology, \& Human Values, 31(3), 237-260.

[13] Cohen, S. (1988). Perceived stress in a probability sample of the United States.

[14] Danish, R. Q., Ramzan, S., \& Ahmad, F. (2013). Effect of perceived organizational support and work environment on organizational commitment; the mediating role of self-monitoring. Advances in Economics and Business, 1(4), 312-317.

[15] Deci, E. L., \& Ryan, R. M. (2010). Selfdetermination. The Corsini encyclopedia of psychology, 1-2.

[16] Dee, J. R., Henkin, A. B., \& Chen, J. H.-H. (2000). Faculty autonomy: perspectives from Taiwan. Higher Education, 40(2), 203-216.

[17] Đerić, M. (2020). What is Autonomy Anyway? Theories of the Self and Autonomy in Medical Ethics (pp. 17-30): Springer.

[18] Dey, T., Kumar, A., \& Kumar, Y. (2014). A new look at the antecedents and consequences of organizational commitment: a conceptual study. Published in International Journal of Humanities and Social Sciences.

[19] Driedonks, B. A., Gevers, J. M., \& van Weele, A. J. (2010). Managing sourcing team effectiveness: The need for a team perspective in purchasing organizations. Journal of Purchasing and Supply Management, 16(2), 109-117. 
[20] Dude, D. J. (2012). Organizational commitment of principals: The effects of job autonomy, empowerment, and distributive justice.

[21] Farrukh, M., Wei Ying, C., \& Abdallah, Ahmed, N. O. (2016). Organizational commitment: Does religiosity matter? Cogent Business \& Management, 3(1), 1239300.

[22] Farrukh, M., Ying, C. W., \& Mansori, S. (2017). Organizational commitment: an empirical analysis of personality traits. Journal of Work-Applied Management.

[23] Fornell, C., \& Larcker, D. F. (1981). Evaluating structural equation models with unobservable variables and measurement error. Journal of marketing research, 18(1), 39-50.

[24] Giffords, E. D. (2009). An examination of organizational commitment and professional commitment and the relationship to work environment, demographic, and organizational factors. Journal of Social Work, 9(4), 386-404.

[25] Haggins, R. (2011). A correlational study of work environment factors and organizational commitment in southern California staff nurses. The University of Phoenix.

[26] Hair, Jr, J. F., Hult, G. T. M., Ringle, C., \& Sarstedt, M. (2016). A primer on partial least squares structural equation modeling (PLS-SEM): Sage publications.

[27] Halldorsson, B., Castelijn, S., \& Creswell, C. (2019). Are children with social anxiety disorder more likely than children with other anxiety disorders to anticipate poor social performance and reflect negatively on their performance? Journal of Affective Disorders, 245 , 561-568. doi:https://doi.org/10.1016/j.jad.2018.11.021

[28] Hanaysha, J. (2016). Testing the effects of employee engagement, work environment, and organizational learning on organizational commitment. Procedia-Social and Behavioral Sciences, 229(8), 289-297.

[29] Hayat, A., Azeem, M., Nawaz, R., Humayon, D. A. A., \& Ahmed, D. M. (2019). Mediating Effect of Human Capital on Organizational Culture, Teamwork, Organizational Development, and Organizational Commitment. Journal of Social Sciences and Humanity Studies, 5(3), 1-9.

[30] Hendri, M. I. (2019). The mediation effect of job satisfaction and organizational commitment to the corporate learning effect of employee performance. International Journal of Productivity and Performance Management.

[31] Hendri, N. (2019). The impact of organizational commitment on job performance.

[32] Henseler, J., Ringle, C. M., \& Sarstedt, M. (2015). A new criterion for assessing discriminant validity in variance-based structural equation modeling. Journal of the academy of marketing science, 43(1), 115-135.

[33] Hsu, H.-Y. (2009). Organizational learning culture influences job satisfaction, organizational commitment, and turnover intention among $\mathrm{R} \& \mathrm{D}$ professionals in Taiwan during an economic downturn.

[34] Igbaria, M., \& Greenhaus, J. H. (1992). Determinants of MIS employees' turnover intentions: a structural equation model. Communications of the ACM, 35(2), 34-49.

[35] Ilyash, O., Yildirim, O., Capuk, S., \& Bozgul, N. (2019). The Impact of Work Autonomy and Organizational Commitment on Organizational Communication. Journal of Behavior Studies in Organizations, 2, 10-17.

[36] Jain, P., \& Duggal, T. (2018). Transformational leadership, organizational commitment, emotional intelligence, and job autonomy. Management Research Review.

[37] Jernigan, E., Beggs, J. M., \& Kohut, G. F. (2016). AN EXAMINATION OF NURSES'WORK ENVIRONMENT AND ORGANIZATIONAL COMMITMENT. Journal of Organizational Culture, Communications, and Conflict, 20(1), 112.

[38] Joe-Akunne, C., \& Ezeh, L. N. (2019). ORGANIZATIONAL COMMITMENT AMONG PRIVATE SECTOR WORKERS IN ANAMBRA STATE, NIGERIA. Practicum Psychologia, 9(1).

[39] Joo, B. K. B., \& Park, S. (2010). Career satisfaction, organizational commitment, and turnover intention. Leadership \& Organization Development Journal.

[40] Karim, N. H. A. (2017). THE IMPACT OF WORK-RELATED VARIABLES ON LIBRARIANS'ORGANIZATIONAL COMMITMENT AND JOB SATISFACTION. Malaysian Journal of Library \& Information Science, 15(3), 149-163.

[41] Karunarathne, E., \& Wickramasekara, A. (2020). MIDDLE-LEVEL 
MANAGERS'ORGANIZATIONAL

COMMITMENT ON THEIR JOB

PERFORMANCE IN AGRICULTURAL INPUT DISTRIBUTING COMPANIES IN SRI LANKA. International Journal of Information, Business, and Management, 12(4), 28-38.

[42] Khan, S. K., Kumar, K. R., \& Vytialingam,

L. K. (2016). A STUDY OF ORGANISATION CITIZENSHIP BEHAVIOUR, JOB AUTONOMY, AND ORGANISATIONAL RESOURCES TOWARDS ORGANISATION COMMITMENT IN PRIVATE SCHOOLS IN MALAYSIA. International Academic Research Journal of Social Science, 2(1), 42-48.

[43] Khuong, M. N., \& Le Vu, P. (2014). Measuring the effects of drivers organizational commitment through the mediation of job satisfaction: A Study in Ho Chi Minh City, Vietnam. International Journal of Current Research and Academic Review, 2(2), 1-16.

[44] Kline, R. B. (2011). The convergence of structural equation modeling and multilevel modeling: na.

[45] Kumasey, A. S., Bawole, J. N., \& Hossain, F. (2017). Organizational commitment of public service employees in Ghana: do codes of ethics matter? International Review of Administrative Sciences, 83(1_suppl), 59-77.

[46] Kwon, I. W. G., \& Banks, D. W. (2004). Factors related to the organizational and professional commitment of internal auditors. Managerial Auditing Journal.

[47] Lin, J. T. P., \& Ping, N. C. L. (2016). Perceived job autonomy and employee engagement as predictors of organizational commitment. Undergraduate Journal of Psychology, 29(1), 1 to 16-11 to 16.

[48] Loon Hoe, S., \& McShane, S. (2010). Structural and informal knowledge acquisition and dissemination in organizational learning. The Learning Organization, 17(4), 364-386.

[49] Lu, J. G., Brockner, J., Vardi, Y., \& Weitz, E. (2017). The dark side of experiencing job autonomy: Unethical behavior. Journal of Experimental Social Psychology, 73, 222-234.

[50] Marchese, M. C., \& Ryan, J. (2001). Capitalizing on the benefits of utilizing part-time employees through job autonomy.
Journal of Business and Psychology, 15(4), 549-560.

[51] McGuire, D., \& McLaren, L. (2009). The impact of the physical environment on employee commitment in call centers. Team Performance Management: An International Journal.

[52] Mehrabi, J., Jadidi, M., Haery, F. A., \& Alemzadeh, M. (2013). The relationship between organizational commitment and organizational learning (Boroojerd Telecommunication Company as a case study). International Journal of Academic Research in Business and Social Sciences, 3(1), 130.

[53] Moe, N. B., Dahl, B., Stray, V., Karlsen, L. S., \& Schjødt-Osmo, S. (2019). Team autonomy in large-scale agile. Paper presented at the Proceedings of the 52nd Hawaii International Conference on System Sciences.

[54] Morgeson, F. P., Delaney-Klinger, K., \& Hemingway, M. A. (2005). The importance of job autonomy, cognitive ability, and job-related skill for predicting role breadth and job performance. Journal of applied psychology, 90(2), 399.

[55] Mowday, R. T., Steers, R. M., \& Porter, L. W. (1979). The measurement of organizational commitment. Journal of vocational behavior, 14(2), 224-247.

[56] Myjoyonline (2019). Political interference stifling public sector productivity. Retrieved from

https://www.myjoyonline.com/news/national /political-interference-stifling-public-sectorproductivity-ae-bentil//

[57] Naim, M. F., \& Lenka, U. (2018). Organizational learning and Gen Y employees' affective commitment: The mediating role of competency development and strategic leadership's moderating role. Journal of Management \& Organization, $1-17$.

[58] Naqvi, S., Kanwal, N., Ishtiaq, M., \& Ali, M. (2013). Impact of job autonomy on organizational commitment: Moderating job satisfaction in the Tobacco industry of Pakistan. Far East Journal of Psychology and Business, 12(5), 57-72.

[59] Naqvi, S. R., Ishtiaq, M., Kanwal, N., \& Ali, M. (2013). Impact of job autonomy on organizational commitment and job satisfaction: The moderating role of corporate culture in Pakistan's fast-food sector. 
International Journal of Business and Management, 8(17), 92.

[60] NGUYEN, T. H., \& TU, V. B. (2020). Social responsibility, organizational commitment, and organizational performance: Food processing enterprises in the Mekong River Delta. The Journal of Asian Finance, Economics, and Business, 7(2), 309-316.

[61] Niemiec, C. P., \& Ryan, R. M. (2009). Autonomy, competence, and relatedness in the classroom: Applying self-determination theory to educational practice. Theory and research in Education, 7(2), 133-144.

[62] Nnamaganda, E. (2019). Job autonomy, organizational commitment, and job performance among Makerere University lecturers. Makerere University.

[63] Ong, G. P., Kasim, R. S. R., \& Uli, J. (2008). The effect of organizational learning on job commitment, job satisfaction, and work performance in Malaysia: a mediation analysis. The International Journal of Knowledge, Culture and Change Management, 8(8), 13-21.

[64] Owusu, F. Y. (2012). Organizational culture and public sector reforms in a postWashington consensus era: Lessons from Ghana's right reformers. Progress in Development Studies, 12(2-3), 135-151.

[65] Park, R., \& Searcy, D. (2012). Job autonomy as a predictor of mental well-being: The moderating role of quality-competitive environment. Journal of Business and Psychology, 27(3), 305-316.

[66] Pfister, J. A., \& Lukka, K. (2019). The interrelation of controls for autonomous motivation: A field study of productivity gains through pressure-induced process innovation. The Accounting Review, 94(3), 345-371.

[67] Pitaloka, E., \& Sofia, I. P. (2014). The effect of the work environment, job satisfaction, organization commitment on OCB of internal auditors. International Journal of Business, Economics, and Law, 5(2), 10-18.

[68] Ramírez, A. M., Morales, V. J. G., \& Rojas, R. M. (2011). Knowledge creation, organizational learning, and their effects on organizational performance. Engineering Economics, 22(3).

[69] Salarian, M., Baharmpour, K., \& Habibi, S. (2015). Organizational commitment and its relationship with organizational learning (case study: general directorate of ports and maritime of Mazandaran province). International Journal of Life Science, 5(6), 67-73.

[70] Siders, M. A., George, G., \& Dharwadkar, R. (2001). The relationship between internal and external commitment foci to objective job performance measures. Academy of Management Journal, 44(3), 570-579.

[71] Sungu, L. J., Weng, Q., Hu, E., Kitule, J. A., \& Fang, Q. (2020). How Does Organizational Commitment Relate to Job Performance? A Conservation of Resource Perspective. Human Performance, 33(1), 52-69.

[72] Usefi, S., Nazari, R., \& Zargar, T. (2013). The relationship between organizational learning and organizational commitment in sport organizations. Management and Administrative Sciences Review, 2(6), 682-688.

[73] Vanaki, Z., \& Vagharseyyedin, S. A. (2009). Organizational commitment, work environment conditions, and life satisfaction among Iranian nurses. Nursing \& health sciences, 11(4), 404-409.

[74] Wang, X. (2007). Learning, job satisfaction, and commitment: an empirical study of organizations in China. Chinese Management Studies.

[75] Yahaya, R., \& Ebrahim, F. (2016). Leadership styles and organizational commitment: a literature review. Journal of Management Development.

[76] Yousef, D. A. (2017). Organizational commitment, job satisfaction, and attitudes toward organizational change: A study in the local government. International Journal of Public Administration, 40(1), 77-88.

[77] Zaraket, W. (2017). Impact of Job Involvement on Organizational Commitment: A Case Study of Lebanese Public Sector. International Humanities Studies, 4(3). 